\title{
Survey of adolescents with severe intellectual handicap
}

\author{
J C Asthana, S Sinha, J S Haslam, H M Kingston
}

\begin{abstract}
A diagnostic survey was undertaken of children aged 11 to 19 years in Tameside with severe learning difficulties (intelligence quotient 550). Eighty two children were identified and their medical records reviewed. A specific diagnosis for the retardation was documented in $25(30 \%)$ of the children, 18 of whom had Down's syndrome. A probable aetiology or a disorder of unknown aetiology had been identified in a further $21(26 \%)$ children. To confirm the existing diagnosis, identify new diagnoses, and offer genetic counselling, the parents of 63 children were offered detailed reassessment of their child. Fifty three children were reviewed, and a specific disorder identified in 25 out of 31 previously undiagnosed children. The most frequent diagnoses made were fragile $X$ syndrome and Rett's syndrome. On completion of the survey, 61 of the 82 children $(74 \%)$ had a specific diagnosis or probable aetiology identified, $12(15 \%)$ had associated disorders such as cerebral palsy, and in only nine of the 82 children $(11 \%)$ were there no clues at all to the cause of their retardation.
\end{abstract}

Severe mental retardation occurs with a prevalence of approximately $3-4 / 1000$ of the general population. It is not always possible to identify a specific aetiology for severe mental retardation, but it is important to reach a diagnosis wherever possible as this enables information to be given to parents about the cause and ultimate prognosis for their child's disorder, as well as determining recurrence risks for future children of the parents and other relatives. Reassessment of affected individuals is important as new disorders associated with mental retardation are identified, and improved cytogenetic techniques enable the detection of subtle structural chromosomal abnormalities such as interstitial deletions.

Surveys of severely retarded individuals (intelligence quotient (IQ) $\leqslant 50$ ) undertaken before the identification and description of the fragile $\mathrm{X}$ syndrome documented a defined cause for the retardation in approximately $50 \%$ of cases. ${ }^{1-3}$ More recent surveys of severely retarded institutionalised patients have demonstrated a defined disorder or aetiology in $82-88 \%$ of cases. ${ }^{45}$

The excess of affected males with non-specific mental retardation has been recognised for many years, and Rosanoff $(1931)^{6}$ and Penrose $(1938)^{7}$ suggested $X$ linked recessive inheritance as a major cause of mental deficiency. The fragile $\mathrm{X}$ chromosome was first demonstrated by Lubs in $1969,{ }^{8}$ and its folic acid dependent expression and association with mental retardation reported in $1977.9^{10}$ The definition of the clinical syndrome during the late 1970s and early 1980s is summarised by Fryns. ${ }^{11}$ This disorder is now thought to be the second most common cause of mental retardation after Down's syndrome, with an estimated prevalence of $0 \cdot 3-1 / 1000$ males and $0 \cdot 2-0.6 /$ 1000 females. ${ }^{12-14}$ Identification of this inherited disorder in retarded children is important because of the genetic implications. Many aspects of the condition are not understood, however, ${ }^{15}$ including transmission by apparently unaffected males, and the high proportion of heterozygous females who have some intellectual impairment usually of mild to moderate degree.

The present study initiated by one of the authors (JCA) was undertaken to identify severely retarded children with fragile $X$ syndrome in the Tameside borough, and where possible to reach a diagnosis in other children with previously unexplained severe retardation, so that families could be offered genetic counselling.

Patients and methods

The study population was drawn from children aged 11 to 19 years attending special schools in Tameside for children with severe intellectual handicap (IQ $\leqslant 50$ ). At the start of the study the estimated total school population aged 11 to 19 years in Tameside was 27585 (13 851 boys, 13734 girls), and all children with severe retardation of this age in the borough received special education at one of two special schools. Eighty two severely retarded children were identified, giving a prevalence of $3 / 1000$ population in Tameside, which is comparable with the general population prevalence, and probably represents fairly complete ascertainment of severe mental retardation in the borough.

The secondary school age group was chosen because children with intellectual handicap under the age of 11 years in Tameside have all been assessed by a multidisciplinary team at the child development unit, and have been fully investigated. The older children had all been assessed in early childhood by a paediatrician before the child development unit was established, and details of prenatal and postnatal histories and early childhood development were well documented. Not all of these children were attending hospital based follow up clinics, however, as their general health was good and their retardation non-progressive. They had not 
had recent detailed re-evaluation, although they all received annual medical examinations at school by a senior clinical medical officer.

Of the 82 children identified with severe retardation, 18 had Down's syndrome (14 boys, four girls) and one had suffered a severe head injury in a road traffic accident. These children were excluded from detailed review as there was no doubt about the aetiology of their retardation. The parents of the remaining 63 children were asked whether they wished to have a detailed reassessment of their child performed jointly by the school senior clinical medical officer, a clinical geneticist, and a paediatrician. The reassessment included taking a history covering the pregnancy and perinatal period, early childhood development, and the general health of the child. The family pedigree with all relevant details was documented, and a full physical examination of the child undertaken, with particular attention paid to clinical measurements, dysmorphic features, or abnormal neurological signs. Further investigations were done when clinically indicated, including screening for fragile $\mathrm{X}$ syndrome in children without dysmorphic features in whom no other aetiology or diagnosis was apparent.

All the cytogenetic analyses were performed by one of the authors (JSH). Three 72 hour lymphocyte cultures were set up from each sample for fragile X studies, using $0.5 \mathrm{ml}$ of whole blood and $4 \mathrm{ml}$ of medium. The first culture used Roswell

Table 1 Diagnostic classification of 82 severely retarded children obtained from previous hospital records

\begin{tabular}{|c|c|c|c|}
\hline Classification & Boys & Girls & Total \\
\hline $\begin{array}{l}\text { Diagnosed disorder: } \\
\text { Down's syndrome } \\
\text { Head injury (road traffic accident) } \\
\text { Tuberous sclerosis } \\
\text { Williams syndrome } \\
\text { Fanconi's syndrome } \\
\text { Angelman's syndrome } \\
\text { Congenital toxoplasmosis } \\
\text { (Subtotal) }\end{array}$ & $\begin{array}{r}14 \\
1 \\
2 \\
0 \\
1 \\
0 \\
1 \\
(19)\end{array}$ & $\begin{array}{l}4 \\
0 \\
0 \\
1 \\
0 \\
1 \\
0 \\
(6)\end{array}$ & $\begin{array}{c}18 \\
1 \\
2 \\
1 \\
1 \\
1 \\
1 \\
(25)\end{array}$ \\
\hline $\begin{array}{l}\text { Probable aetiology identified: } \\
\text { Agenesis corpus callosum } \\
\text { Birth asphyxia } \\
\text { Cyanotic heart disease } \\
\text { Subdural haematoma } \\
\text { Prolonged febrile convulsions } \\
\text { Hypernatraemic dehydration (Subtotal) }\end{array}$ & $\begin{array}{l}0 \\
0 \\
1 \\
0 \\
1 \\
0 \\
(2)\end{array}$ & $\begin{array}{r}1 \\
4 \\
0 \\
1 \\
0 \\
1 \\
(7)\end{array}$ & $\begin{array}{r}1 \\
4 \\
1 \\
1 \\
1 \\
1 \\
(9)\end{array}$ \\
\hline $\begin{array}{l}\text { Disorder of unknown aetiology: } \\
\text { Cerebral palsy } \\
\text { Epilepsy } \\
\text { Dysmorphic syndrome } \\
\text { Autism } \\
\text { (Subtotal) }\end{array}$ & $\begin{array}{c}0 \\
2 \\
4 \\
1 \\
(7)\end{array}$ & $\begin{array}{c}2 \\
2 \\
0 \\
1 \\
(5)\end{array}$ & $\begin{array}{c}2 \\
4 \\
4 \\
2 \\
(12)\end{array}$ \\
\hline Unidentified disorder & 20 & 16 & 36 \\
\hline Total & 48 & 34 & 82 \\
\hline
\end{tabular}

Table 2 Diagnoses made during the survey in 25 of 31 previously unclassified children

\begin{tabular}{lccc}
\hline Diagnosis & Boys & Girls & Total \\
\hline Fragile X syndrome & 11 & 4 & 15 \\
Rett's syndrome & 0 & 5 & 5 \\
Chromosomal abnormality & 1 & 0 & 1 \\
Angelman's syndrome & 0 & 2 & 2 \\
Congenital myotonic dystrophy & 1 & 0 & 1 \\
Behr's syndrome & 1 & 0 & 1 \\
\hline Total & 14 & 11 & 25 \\
\hline
\end{tabular}

Park Memorial Institute 1640 medium with penicillin/streptomycin, glutamine, and $20 \%$ fetal calf serum. Thymidine was added to a final concentration of $380 \mathrm{mg} / \mathrm{l} 22$ hours before harvest, and this block was released five hours before harvest with 2-deoxycytidine $(2 \cdot 28 \mathrm{mg} / \mathrm{l})$. The second culture was set up under the same conditions but the thymidine block was not released. The third culture used $199+$ Hepes medium with penicillin/streptomycin, glutamine, and $5 \%$ fetal calf serum. A total of 100 mitoses were analysed in boys and 150 in girls.

The parents of 10 children requested no reassessment or failed to reply, and 53 children were therefore seen during the survey.

\section{Results}

The existing diagnoses or identified aetiologies shown in table 1 were confirmed during the survey. New diagnoses reached in 25 cases are listed in table 2.

During the survey chromosome cultures for fragile $\mathrm{X}$ studies were done in 15 boys and 11 girls. Positive results were found in 11 boys ( $3-45 \%$ positive cells) and four girls (4-6\% positive cells). Not all of these children had the physical characteristics of the syndrome, although seven boys and one girl did have large jaws, large ears, or prominent foreheads. The 15 children diagnosed came from 12 families, with three pairs of affected siblings being identified in the study population: two sets of brothers and one brother and sister. In two families there was a previous family history of mental retardation suggesting an $\mathrm{X}$ linked recessive pattern of inheritance. In the remaining seven families the retarded child was the only affected person in the family.

All the mothers of the affected children identified agreed to have fragile $\mathrm{X}$ studies performed on themselves. Seven out of eight mothers of the affected boys were fragile $\mathrm{X}$ positive (2-14\% positive cells), and two of these women had a low IQ. The mothers of the four isolated affected girls were all fragile $\mathrm{X}$ negative and had normal IQs. One obligate carrier, with an affected son and two affected daughters, did not demonstrate the fragile $\mathrm{X}$ chromosome on analysis.

Ten sisters of affected probands were tested. Two were fragile $X$ positive, of whom one had a low IQ. Eight were fragile X negative, of whom two had a low IQ. Seven out of 15 maternally related aunts and cousins potentially at risk have so far been tested, and all were fragile $\mathrm{X}$ negative. DNA analysis using linked restriction fragment length polymorphisms is currently being performed in families of suitable structure.

Standard chromosome analysis was performed in 17 children in addition to those found to be fragile X positive. One boy who had no dysmorphic features was found to have extra unidentified chromosomal material attached to the short arm of one chromosome $12(46, \mathrm{XY}$, $(12 p+))$. No chromosomal abnormalities were detected in the other 16 cases, including three boys with multiple congenital abnormalities. Literature review together with a syndrome data base search failed to show a definitive 
diagnosis in these boys. ${ }^{16}$ Chromosome $15 q$ deletions were not detected in the two girls with clinically diagnosed Angelman's syndrome from whom samples could be obtained.

Five girls were diagnosed as having Rett's syndrome. All had been born at full term after normal pregnancies and there were no perinatal problems apart from mild and transient feeding difficulties in four. Developmental regression was documented in all five girls, starting between the ages of 6 and 18 months. In two girls the regression had previously been attributed by the parents to whooping cough vaccination, and in another to a relatively mild episode of gastroenteritis. Normal head circumference at birth with subsequent microcephaly was documented in all five girls. All had typical stereotyped hand movements, and none had useful manipulation skills. Two girls had never been able to walk, the other three had an unsteady gait but were ambulant with help. All five girls had abnormal recordings on electroencephalography and clinical epilepsy, which had become easier to control in three girls from the ages of 8,9 , and 16 years respectively. Scoliosis of varying degree was present in four, and four had poor peripheral circulation. All the girls had increased limb tone, brisk reflexes, and periods of hyperventilation. One girl required oxygen treatment and was too ill to attend school. She died from respiratory failure during the course of the survey. No biochemical abnormalities were detected in any of the girls, and computed tomography of the brain performed in one showed no structural abnormality of the central nervous system. Family history was negative in all five cases.

One case of Behr's syndrome (inherited spinocerebellar degeneration with posterior column loss, optic atrophy, and mental retardation) and another of congenital myotonic dystrophy were identified during the survey, and the diagnosis confirmed on referral to neurology clinics.

Perinatal and postnatal factors previously thought to have been implicated in the mental retardation in six cases were confirmed. These included three children with severe birth asphyxia, one child a subdural haematoma occurring at 3 months of age, another with hypernatraemic dehydration and convulsions during a severe gastroenteritic illness, and one child with a febrile convulsion lasting over an hour and a half at the age of 2 years.

No diagnosis was reached in eight of the children reviewed. These children included two with epilepsy, one of whom had moderately retarded parents. There was no positive family history in the remaining six children.

The case notes of the 10 children whose parents declined reassessment were reviewed, and showed no identifiable aetiology in three. Two of the children were brothers, suggesting a genetic aetiology, and they did have clinical features compatible with the fragile $\mathrm{X}$ phenotype. Among the remaining five, there was probable birth asphyxia in one, severe cyanotic heart disease and Eisenmenger's syndrome in one, dysmorphic features and parental consanguinity in one, and epilepsy in two of whom one child was autistic and the other had moderately retarded relatives.

At the end of the survey a diagnosis or probable aetiology could be identified for 61 of the 82 children (74\%). In a further 12 children (15\%) there were associated disorders such as cerebral palsy, epilepsy, autism, or congenital abnormalities of unknown aetiology. The retardation remained completely unexplained in nine (11\%) children (four boys, five girls).

\section{Discussion}

During the study period, a diagnosis was made in 25 out of 31 children in whom there had previously been no aetiology identified for their retardation. As expected from reports of other school surveys, ${ }^{17} 18$ fragile $X$ syndrome was the most frequently diagnosed disorder.

Establishing a diagnosis enabled genetic information to be given to the families, many of whom had children or other relatives reaching reproductive age who were concerned about risks of recurrence. The genetic implications for relatives are particularly important when a diagnosis of fragile $\mathrm{X}$ syndrome is made. During this survey, apart from one family where the affected boy's mother did not wish to inform her sisters and nieces of the diagnosis, the relatives of children with fragile $X$ syndromes all took up the offer of genetic counselling and further investigation. Most female relatives at, or reaching, reproductive age who were potentially at risk felt that they would wish to avail themselves of prenatal diagnosis in the future.

The prevalence of fragile $\mathrm{X}$ syndrome in severely retarded children in Tameside estimated from this survey is $0.8 / 1000$ boys and $0 \cdot 3 / 1000$ girls. Children with mild to moderate learning difficulties (IQ 50-70) were not reviewed, and this group of children in Tameside may contain further cases of fragile $\mathrm{X}$ syndrome, particularly girls, although this disorder has not always been identified in surveys of children with mild to moderate disability. ${ }^{19}$

In contrast to fragile $\mathrm{X}$ syndrome, other chromosomal abnormalities, which may be found more commonly in children with mild mental retardation, ${ }^{20}$ were detected in only one case in the present survey.

The diagnosis of Rett's syndrome in five girls gives a prevalence in Tameside of $3 \cdot 6 / 10000$ girls. This is considerably higher than the estimated prevalence of $0.8 / 10000$ girls up to the age of 14 years that has been previously reported. ${ }^{20-23}$ Rett's syndrome was first described in $1966,{ }^{24}$ and to date no biochemical or chromosomal abnormality has been consistently found in affected girls. Confirmation of the diagnosis will be important when the underlying biochemical or genetic defect is defined. The five girls in the present survey did fulfil all the diagnostic criteria for Rett's syndrome delineated during the 1986 workshop on the disorder, ${ }^{25-27}$ and summarised by Hagberg. ${ }^{28}$ These clinical features include female sex and a normal prenatal and perinatal period with early normal development. This is followed by deterioration and loss of skills, 
normal head circumference at birth with decelleration of head growth in early childhood, loss of purposeful hand skill, development of hand ringing and clapping stereotypes, and appearance of gait and truncal apraxia by the age of 4 years. Four clinical stages in classical Rett's syndrome have been described, and the girls in this survey corresponded to stages III and IV, representing a severe multihandicap syndrome with decreasing mobility, scoliosis, and the development of paraplegic or tetraplegic signs. Familial recurrence of Rett's syndrome is infrequently reported, ${ }^{28}{ }^{29}$ and low recurrence risks are generally quoted. There were no positive family histories in any of the five girls identified during this survey.

In nine children in this survey population there were no clues to the underlying diagnosis or cause of their retardation. Precise calculation of recurrence risks to use when counselling relatives of these children is difficult. Figures are generally based on reported recurrence risks of between $2-10 \%$ observed in siblings in previous studies of severe non-specific retardation. ${ }^{30-36}$ These surveys report an excess of male cases, and higher recurrence risks when the proband is male, probably influenced by the inclusion of some undiagnosed families with fragile $X$ syndrome, as well as cases of nonspecific $X$ linked mental retardation.

The results of the present survey indicate that reassessment of severely retarded children without a diagnosis is of value, and should be considered as part of the regular medical review of children attending special schools. The majority of parents appreciated the review and the chance to discuss their child's problems at length, even when no diagnosis could ultimately be offered. Although most parents had completed their own families, genetic counselling was appropriate as siblings and other relatives were reaching reproductive age.

We wish to thank all the parents who cooperated with this survey, and are grateful to Vera Hobson, community nursing survey, and are grateful to Vera Hobson, community nursing
sister, and the staff of Cromwell and Oakdale Special Schools for sister, and the staff of Cromwell and Oakdale Special Schools for
their help in arranging the medical reviews of the children.

1 Laxova R, Ridler MAC, Bowen-Bravery M. An etiological survey of the severely retarded in Hertfordshire children who were born between January 11965 and December 31 1967. Am J Med Genet 1977;1:75-86.

2 Gustavson KH, Hagberg B, Hagberg G, Sars K. Severe mental retardation in a Swedish county. II. Etiological and pathogenetic aspects of children born 1959-1970. Neuropathogenetic aspects of ch.
padiätrie 1977;8:293-304.

3 Kaveggia EG, Durkin MV, Pendleton E, Opitz JM. Diagnostic/genetic studies in 1224 patients with severe mental retardation. Proceedings of the 3rd Congress of the International Association for the Scientific Study of Mental Deficiency. Warsaw: Polish Medical Publishers, 1975:82-93.

4 Fryns JP, Kleczkowska A, Dereymaeker A, et al. A genetic-diagnostic survey in an institutionalized population of 173 severely mentally retarded patients. Clin Genet 1986;30:315-23.
5 Dereymaeker AM, Fryns JP, Haegeman J, Deroover J, Van den Berghe H. A genetic-diagnostic survey in an instituden Berghe $\mathbf{H}$. A genetic-diagnostic survey in an instituThe Viaene experience. Clin Genet 1988;34:126-34.

6 Rosanoff AJ. Sex-linked inheritance in mental deficiency. Am F Psychiatry 1931;11:289-97.

7 Penrose LS. A clinical and genetic study of 1280 cases of mental defect. London: Medical Research Council, 1938. (Special Report Series No 229.)

8 Lubs HA. A marker X chromosome. Am 7 Hum Gene 1969;21:231-44.

9 Harvey J, Judge C, Wiener S. Familial X-linked retardation with an X chromosome abnormality. F Med Genet 1977;14 46-50.

10 Sutherland GR. Fragile sites on human chromosomes: demonstration of their dependence on the type of tissue culture medium. Science 1977;197:265-6.

11 Fryns JP. X-linked mental retardation and the fragile $X$ syndrome: a clinical approach. In: Davies KE, ed. The fragile $X$ syndrome. Oxford: Oxford University Press, fragile $X$.

12 Webb TP, Bundey SE, Thake AI, Todd J. Population incidence and segregation ratios in the Martin-Bell syndrome. Am 7 Med Genet 1986;23:573-80.

13 Turner G, Robinson H, Laing S, Purvis-Smith S. Preventive screening for the fragile X syndrome. $N$ Engl $\mathcal{f} \mathrm{Med}$ 1986;315:607-9.

14 Kähkönen M, Alitalo T, Airaksinen E, et al. Prevalence of the fragile $\mathrm{X}$ syndrome in four birth cohorts of children of school age. Hum Genet 1987;77:85-7.

15 Winter RM. Fragile X mental retardation. Arch Dis Child 1989;64:1223-4.

16 Winter RM, Baraitser M, Douglas JM. A computerised data base for the diagnosis of rare dysmorphic syndromes. $\mathcal{f}$ Med Genet 1984;21:121-3.

17 Webb TP, Bundey S, Thake A, Todd J. The frequency of the fragile $\mathrm{X}$ chromosome among schoolchildren in Coventry. f Med Genet 1986;23:396-9.

18 Li S-Y, Tsai C-C, Chou M-Y, Lin J-K. A cytogenetic study of mentally retarded school children in Taiwan with special reference to the fragile X chromosome. Hum Genet 1988; reference to:

19 Lamont MA, Dennis NR. Aetiology of mild mental retardation. Arch Dis Child 1988;63:1032-8

20 Lamont MA, Dennis NR, Seabright $M$. Chromosome abnormalities in pupils attending $\operatorname{ESN}(\mathbf{M})$ schools. Arch Dis Child 1986;61:223-6.

21 Hagberg BA. Rett's syndrome. Prevalence and impact on progressive severe mental retardation in girls. Acta Paediatr Scand 1985;74:405-8.

22 Kerr AM, Stephenson JBP. Rett's syndrome in the west of Scotland. Br Med F 1985;291:579-82.

23 Kerr AM, Stephenson JBP. A study of the natural history of Rett syndrome in 23 girls. Am F Med Genet 1986;24:77-83.

24 Rett A. Über ein eigenartiges hirnatrophisches Syndrom bei Hyperammonämie im Kindesalter. Wien Med Wochenschr 1966;116:723-6.

25 Hagberg B, Witt-Engerström I. Rett syndrome: a suggested staging system for describing impairment profile with increasing age towards adolescence. Am $\mathcal{F}$ Med Genet $1986 ; 24: 47-59$

26 Naidu S, Murphy M, Moser HW, Rett A. Rett syndromenatural history in 70 cases. Am F Med Genet 1986;24:61-72. Budden SS. Rett syndrome: studies of 13 affected girls. $A m \dot{F}$ Med Genet 1986;24:99-109.

28 Hagberg BA. Rett syndrome: clinical peculiarities, diagnostic approach, and possible cause. Pediatric Neurology 1989;5: 75-83.

29 Romeo G, Archidiacono N, Ferlini A, Rocchi M. Rett syndrome. Lack of association with fragile site $\mathrm{Xp} 22$ and strategy for genetic mapping of X-linked new mutations. Am ₹ Med Genet 1986;24:355-9.

30 Penrose LS. The biology of mental defect. London: Sidgwick and Jackson, 1972:120-33.

31 Bundey S, Carter CO. Recurrence risks in severe undiagnosed mental deficiency. $\mathcal{J}$ Ment Defic Res 1974;18:115-34. nosed mental deficiency. F Ment Defic Res 1974;18:115-34.
Angeli E, Kirman B. Genetic prognosis in severe mental Angeli E, Kirman B. Genetic prognosis in
defect. $\mathcal{F}$ Ment Defic Res 1975;19:173-93.

33 Turner G, Collins E, Turner B. Recurrence risk of mental retardation in sibs. Med $\mathcal{f}$ A Aust 1971;1:1165-8.

34 Becker JM, Kaveggia EG, Pendleton E, Opitz JM. A biologic and genetic study of 40 cases of severe pure mental retardation. Eur f Pediatr 1977;124:231-56.

35 Herbst DS, Baird PA. Sib risks for non-specific mental retardation in British Columbia. Am F Med Genet 1982;13: 197-208.

36 Costeff $H$, Weller $L$. The risk of having a second retarded child. Am $\mathcal{J}$ Med Genet 1987;27:753-66. 